\title{
ARMAZENAMENTO REFRIGERADO DE POMELOS VARIEDADES FLAME E HENDERSON REVESTIDOS COM CERA
}

\author{
Refrigerated storage of wax-coated grapefruit varieties Flame and Henderson \\ Ellen Toews Doll Hojo', Ronaldo Hissayuki Hojo², Eduardo Valério de Barros Vilas Boas ${ }^{3}$, \\ Luiz José Rodrigues ${ }^{3}$, Nélio Ranieli Ferreira de Paula ${ }^{3}$
}

\begin{abstract}
RESUMO
Objetivou-se, neste trabalho, estudar a conservação de pomelos (Citrus paradisi Macfad.) varieties 'Flame' e 'Henderson' revestidos com cera Sparcitrus e mantidos sob refrigeração $\left(8^{\circ} \mathrm{C} \pm 1^{\circ} \mathrm{C}\right.$ e $95 \% \pm 5 \%$ UR). Para cada variedade estudada, utilizouse delineamento inteiramente casualizado, disposto em esquema fatorial 2 x 5 , com 3 repetições, onde o primeiro fator correspondeu aos tratamentos com e sem a aplicação de cera (controle) e o segundo, ao tempo armazenamento (0,10, 20, 30 e 40 dias). Cada parcela experimental foi composta por cinco frutos. Foram estudadas as seguintes variáveis: perda de massa, rendimento do suco, $\mathrm{pH}$, sólidos solúveis (SS), acidez titulável (AT), SS/AT, açúcares redutores, açúcares não redutores, açúcares solúveis totais, vitamina C e aparência externa. A aplicação de cera é efetiva na preservação da aparência de pomelos 'Flame' e 'Henderson', não afetando sua qualidade interna.
\end{abstract}

Termos para indexação: Citrus paradisi Macfad., qualidade, armazenamento, cera.

\begin{abstract}
The goal of this work was to study the conservation of grapefruit (Citrus paradisi Macfad.) "Flame" and "Henderson" coated with Sparcitrus wax and kept under refrigeration $\left(8^{\circ} \mathrm{C} \pm 1^{\circ} \mathrm{C}\right.$ and $\left.95 \% \pm 5 \% \mathrm{RH}\right)$. For each variety studied, the experimental design was completely randomized, build up in factorial $2 \times 5$, with 3 replicates, where the first factor corresponded to the treatments with and without wax application (control) and the second factor to the storage period (0,10,20,30 and 40 days). Each experimental parcel was composed of five fruits. The following variables were studied: mass loss, yield of juice, $\mathrm{pH}$, soluble solids (SS), titratable acidity (TA), SS/AT, reducing, non-reducing and total soluble sugars, ascorbic acid and external appearance. Wax application is effective in the preservation of the appearance of grapefruits "Flame" and "Henderson", and does not affect their internal quality.
\end{abstract}

Index terms: Citrus paradisi Macfad., quality, storage, wax.

(Recebido em 23 de outubro de 2007 e aprovado em 6 de março de 2009)

\section{INTRODUÇÃo}

A espécie Citrus paradisi Macfad. pertence à família Rutaceae Juss., apresentando frutos grandes, com polpa doce-amargo-ácida, sementes poliembriônicas, grandes, cuneiformes, com cotilédones brancos (Simão, 1998). Recebem diferentes denominações no mundo citrícola, sendo conhecidos em português como pomelos.

O cultivo de pomelo é uma atividade de grande importância econômica e os principais países produtores são os Estados Unidos, China, México, Israel, Cuba, África do Sul e Argentina. A produção mundial alcança hoje cerca de 3,45 milhões de toneladas/ano, sendo os Estados Unidos o maior produtor com 1,12 milhões, o que corresponde a $32 \%$ do total. No Brasil, a sua exploração está restrita a pequenos pomares, sendo a sua produção, no ano de 2005 , de 68 mil toneladas e destinada especialmente à exportação (Food and Agriculture Organization - FAO, 2007). O fruto apresenta teor de acidez considerado elevado para os hábitos brasileiros e um sabor doce e amargo que imprime característica peculiar ao suco (Coelho, 2002), entretanto, em virtude da presença do pigmento licopeno na polpa de algumas variedades, exerce grande atratividade sobre o consumidor, tanto pela beleza interna do fruto como pela cor da casca.

O consumidor tem se tornado cada vez mais exigente quanto à qualidade do produto final. Isso tem motivado a preocupação no que se refere á preservação da qualidade da fruta, visando ao prolongamento, no período de comercialização. Assim, a comercialização da maioria dos vegetais frescos pode ser prolongada pelo armazenamento imediato dos mesmos, em condições atmosféricas que mantenham a sua qualidade. Portanto, o

'Universidade Estadual Paulista "Júlio de Mesquita Filho"/UNESP - Faculdade de Ciências Agrárias e Veterinárias/FCAV - Campus de Jaboticabal - Via de Acesso Professor Paulo Donato Castellane - s/n - 14884-900 - Jaboticabal, SP - ellendollhojo@yahoo.com.br

"Universidade Estadual Paulista "Júlio de Mesquita Filho"/UNESP - Faculdade de Ciências Agrárias e Veterinárias/FCAV - Jaboticabal, SP

${ }^{3}$ Universidade Federal de Lavras/UFLA - Departamento de Ciência dos Alimentos/DCA - Lavras, MG 
armazenamento visa a minimizar a intensidade dos processos vitais dos frutos e hortaliças, por meio de condições adequadas, que permitam uma redução do metabolismo normal, sem alterar sua fisiologia (Wills et al., 1998).

O uso de baixa temperatura no armazenamento, realizado de modo adequado, reduz a incidência de doenças pela inibição do crescimento de microrganismos, restringe as atividades enzimáticas e respiratórias, inibe a perda de água, retarda a perda de frescor e qualidade e reduz a produção de etileno (Chitarra \& Chitarra, 2005; Damiani et al., 2008a,b; Pinheiro et al., 2009). A temperatura utilizada durante o armazenamento é de grande importância, pois exerce influência na taxa de respiração e transpiração dos frutos. Excesso de transpiração pós-colheita resulta no enrugamento do fruto, desenvolvimento desuniforme da cor, amadurecimento irregular, afetando também as características sensoriais (Evangelista et al., 2000).

Uma técnica comumente utilizada e associada à refrigeração é o uso de cera. $\mathrm{O}$ uso de ceras ou de emulsões de cera como cobertura superficial em certos produtos perecíveis reduz a perda de umidade e retarda o enrugamento, bem como pode propiciar aparência lustrosa, o que é muito apreciado pelo consumidor (Chitarra \& Chitarra, 2005; Lima et al., 2010). A utilização de cera Sparcitrus evidenciou redução da perda de massa fresca e enrugamento, sem interferir nos teores de sólidos solúveis, índice de $\mathrm{pH}$ e firmeza de abacate 'Fuerte' armazenados em temperatura ambiente (Oliveira et al., 2000). E o uso de cera de carnaúba apresentou maior eficiência na conservação pós-colheita em relação à testemunha, em função da menor percentagem de perda de massa fresca e manutenção de maior teor relativo de água do pericarpo de maracujáamarelo (Mota et al., 2006).

Considerando-se a carência de estudos relativos à pós-colheita de pomelo e ao enceramento sobre a qualidade e vida útil desse fruto, objetivou-se, neste trabalho, estudar a conservação das variedades Flame e Henderson revestidas com cera Sparcitrus e mantidas sob refrigeração.

\section{MATERIAL E MÉTODOS}

O experimento foi conduzido com duas variedades de pomelo (Citrus paradisi Macfad.) de polpa rosaavermelhada: 'Flame' e 'Henderson', ambas cultivadas sobre o porta-enxerto 'Volkameriano`, produzidas em uma propriedade rural localizada no município de Estreito, BA. Após a colheita, os frutos foram transportados sob refrigeração $\left(8^{\circ} \mathrm{C}\right)$ para o Laboratório de Pós-colheita de Frutas e Hortaliças do Departamento de Ciência dos Alimentos, na Universidade Federal de Lavras, MG, onde foram lavados e sanificados com solução de hipoclorito de sódio a $200 \mathrm{mg} \mathrm{L}^{-1}$, durante 15 minutos, selecionados quanto ao tamanho e uniformidade de maturação (estádio de maturação caracterizado pela pigmentação alaranjada da epiderme) e ausência de doenças. Posteriormente, os frutos foram submetidos aos seguintes tratamentos: 1 Imersão em cera Sparcitrus (com 22-23\% polietileno/resina maleica, solvente orgânico), sem diluição; 2 - Controle ( sem cera). Em seguida foram armazenados sob refrigeração $\left(8^{\circ} \mathrm{C} \pm 1^{\circ} \mathrm{C}\right.$ e $95 \% \pm 5 \%$ UR).

Foram estudadas as seguintes variáveis: massa $(\mathrm{g}) \mathrm{e}$ perda de massa (\%) - determinadas, com auxílio de balança semianalítica; aparência externa - por uma escala subjetiva crescente de notas que variou de 1 a 5 , de acordo com a porcentagem de frutos afetados por enrugamento (1: $0 \%$ de danos; 2: 1-25\% de danos; 3: 26-50\% de danos; 4: 51-75\% de danos; 5: 76-100\% de danos), realizada por uma equipe de cinco pessoas; rendimento do suco (\%) com base na fórmula: massa do suco x 100/massa da fruta; $\mathrm{pH}$ - determinado utilizando-se um potenciômetro, segundo técnica da Association of Official Analytical Chemistry AOAC (1992); sólidos solúveis (\%) - determinado por leitura em refratômetro digital, segundo a metodologia da AOAC (1992); acidez titulável (\% de ácído cítrico) - obtida por titulação com NAOH $0,1 \mathrm{~N}$, conforme normas analíticas do Instituto Adolfo Lutz (1985); açúcares redutores, não redutores e totais (\%) - analisados pelo método de Somoghy, modificado por Nelson (1944) e determinados espectrofotometricamente, a $510 \mathrm{~nm}$; vitamina C (mg de ácido ascórbico. $100 \mathrm{~g}^{-1}$ de polpa) - o teor de ácido ascórbico (após a oxidação a ácido dehidroascórbico) foi determinado pelo método colorimétrico, usando o reagente 2,4 dinitrofenilhidrazina, segundo Strohecker \& Henning (1967).

Para cada variedade estudada separadamente, utilizou-se delineamento inteiramente casualizado, disposto em esquema fatorial $2 \times 5$, com 3 repetições, onde o primeiro fator correspondeu aos tratamentos com e sem a aplicação de cera (controle) e o segundo, ao tempo de armazenamento $(0,10,20,30$ e 40 dias). Cada parcela foi composta por cinco frutos. Os resultados foram submetidos à análise de variância pelo teste F. Para a descrição das variáveis em função dos períodos de armazenamento, foram feitas análises de regressão e os modelos polinominais foram selecionados, observando-se a significância do teste F para cada modelo e seus respectivos coeficientes de determinação.

\section{RESULTADOS E DISCUSSÃO}

Para a variedade 'Flame', a massa média dos frutos variou de 231 a $342 \mathrm{~g}$, menor que da variedade Henderson 
que variou de 265 a 381 g. Os valores de massa encontrados para pomelo, neste estudo, são superiores aos relatados por Donadio \& Enciso-Garay (1997), nas condições de Bebedouro-SP, estudando duas variedades de pomelo de polpa rosa-avermelhada: 'Star Ruby' e 'Redblush' e quatro clones de 'Marsh Seedless' (M.S.10, M.S.21, M.S.C e M.S. P), de polpa amarela $(277,95 \mathrm{~g}, 280,60 \mathrm{~g}$, 298,26 g, 259,86 g, 282,13 g e 240,22 g, respectivamente). Esses valores também foram superiores aos encontrados por Lederman et al. (2005), na região semiárida de Pernambuco, com as variedades de polpa rosaavermelhada 'Marsh Foster', 'Star Ruby“, 'Rio Red“ e 'Red Blush ' e uma variedade de polpa amarelada: 'Marsh Foster Nucelar' (303,40 g, 285,50 g, 296,87 g, 291,83 g, 290,33 g, respectivamente). Contudo, os mesmos autores estudando a variedade Triumph, também de polpa amarelada, observaram uma massa média superior de 401,60 g. Coelho (2002) analisou pomelos 'Marsh Seedless“ importados e comercializados no mercado de Salvador-BA, observando massa média de $287 \mathrm{~g}$, inferior a das variedades cultivadas no Brasil. Tais divergências, provavelmente, são decorrentes das diferenças das condições edafoclimáticas dos locais de cultivo ou, ainda, ao uso de clones préimunizados com isolados fracos do vírus da tristeza dos citros, comum no Brasil, e aos porta-enxertos utilizados, como exemplo a tangerina 'Cleopatra', o que pode ter induzido frutos de menor tamanho, conforme relatado por Donadio \& Enciso-Garay (1997).

A perda de massa dos frutos da variedade Flame foi influenciada pelos fatores tempo de armazenamento e tratamento com cera, isoladamente. Observou-se aumento significativo da perda de massa dos frutos independentemente de tratamentos ao longo do armazenamento, que variou de 7,33\% a 23,33\%, dos 10 aos 40 dias de armazenamento (Figura 1A). A perda de massa dos frutos tratados com cera $(10,73 \%)$ foi estatisticamente inferior a dos frutos controle $(13,60 \%)$, demonstrando o efeito da cera em reduzir as perdas e atuando como barreira ao vapor de água (Tabela 1).

Os frutos da variedade Henderson foram influenciados pela interação entre os fatores tempo de armazenamento e tratamento com cera, quanto à perda de massa. Observou-se aumento significativo da perda de massa nos frutos ao longo do armazenamento, tendo os maiores valores sido observados nos frutos controle (Figura 1B). Assim, a cera foi efetiva na contenção de perda de massa, diminuindo e controlando a transpiração dos frutos, promovendo uma importante barreira contra a perda de água.

A perda de água de produtos armazenados não só resulta em perda de massa, mas também em perda de qualidade, principalmente pelas alterações na firmeza e aparência. Alguma perda de água pode ser tolerada, mas não pode ser tão alta que promova murchamento ou enrugamento da casca. Segundo Chitarra \& Chitarra (2005), perdas da ordem de $5 \%$ a $10 \%$ são suficientes para reduzir a qualidade da maioria das frutas e hortaliças, diminuindo o valor de comercialização do produto.

A aplicação de cera influenciou positivamente a aparência dos frutos das duas variedades estudadas, principalmente, a partir do $20^{\circ}$ dia de armazenamento. Os frutos submetidos ao tratamento com cera mostraram-se superiores aos sem cera, das duas variedades estudadas, a partir do $20^{\circ}$ dia, quanto a aparência externa (Figura 2). A perda de água, por transpiração, foi suficientemente alta, afetando a aparência e aceitabilidade do produto.
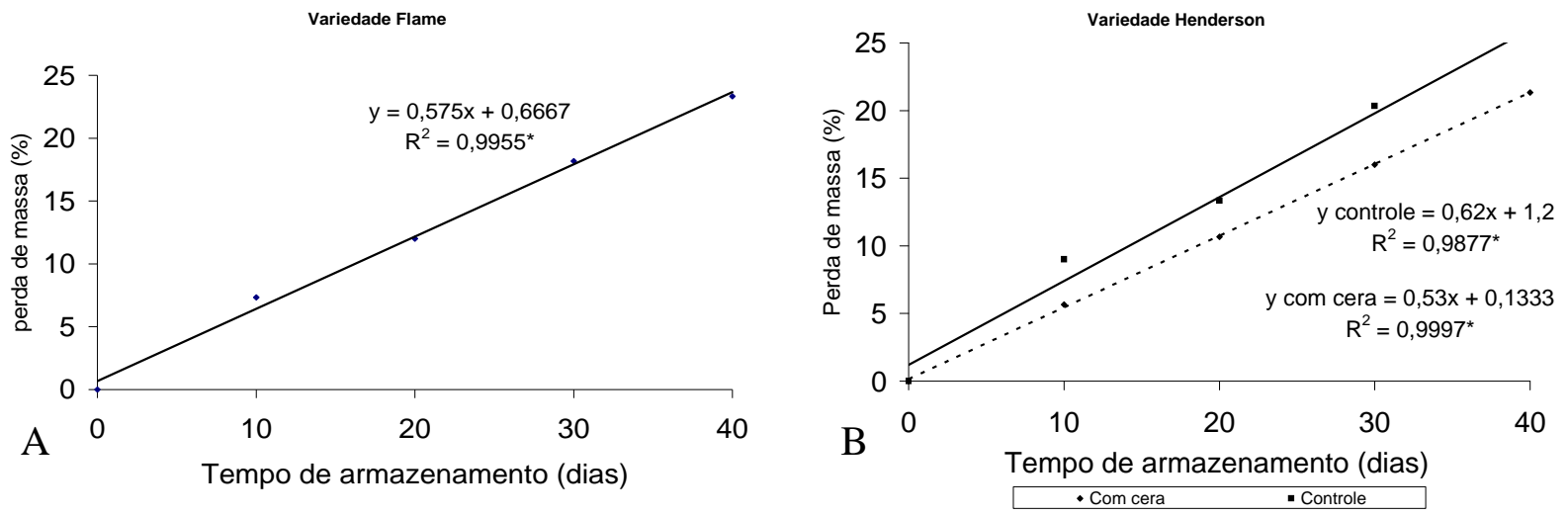

Figura 1 - Perda de massa de pomelos 'Flame' (A) e 'Henderson' (B) tratados com cera, nos diferentes períodos de armazenamento refrigerado $\left(8^{\circ} \mathrm{C} \pm 1^{\circ} \mathrm{C}, 95 \% \pm 5 \% \mathrm{UR}\right)$. 
Tabela 1 - Valores médios de perda de massa (\%) de pomelos tratados com cera e armazenados sob refrigeração, por até 40 dias $\left(8^{\circ} \mathrm{C} \pm 1^{\circ} \mathrm{C}\right.$ e $\left.95 \% \pm 5 \% \mathrm{UR}\right)$.

\begin{tabular}{cc}
\hline Tratamento & Perda de massa $(\%)$ \\
\hline Controle & $13,60 \mathrm{~b}$ \\
Com cera & $10,73 \mathrm{a}$ \\
\hline C.V. $(\%)$ & 19,96 \\
\hline
\end{tabular}

* Médias seguidas de mesma letra não diferem entre si a 5\% de probabilidade pelo teste de Tukey.

O rendimento de suco (RS) do pomelo 'Flame ' não foi influenciado pela cera, tampouco pelo tempo de armazenamento, observando-se valor médio de $51,38 \%$ para todos os frutos.
No entanto, para os frutos 'Henderson', houve efeito significativo da interação entre os fatores estudados para o RS. Nos frutos 'Henderson', a variável RS, apresentou um comportamento quadrático nos frutos com cera, com ponto máximo no $9^{\circ}$ dia e cúbico nos frutos controle, com maior rendimento aos 10 dias e menor aos 32 dias (Figura 3).

O RS médio dos pomelos 'Flame' $(51,38 \%)$ e 'Henderson' $(49,43 \%)$ foi superior ao citado por Donadio \& Enciso-Garay (1997) para 'Star Ruby' (43,13\%), 'Redblush' (40,40\%), 'Marsh Seedless' M.S. 10 (39,78\%), M.S.21 (39,81\%), M.S.C (37,63\%) e M.S. P (38,72\%), cultivadas em BebedouroSP, e por Lederman et al. (2005), para 'Marsh Foster' $(35,2 \%)$, 'Star Ruby' (28,3\%), 'Rio Red“ (41,7\%), 'Red Blush' (39,4\%), 'Marsh Foster Nucelar' (46,0\%) e 'Triumph` $(38,5 \%)$, cultivados em Pernambuco.

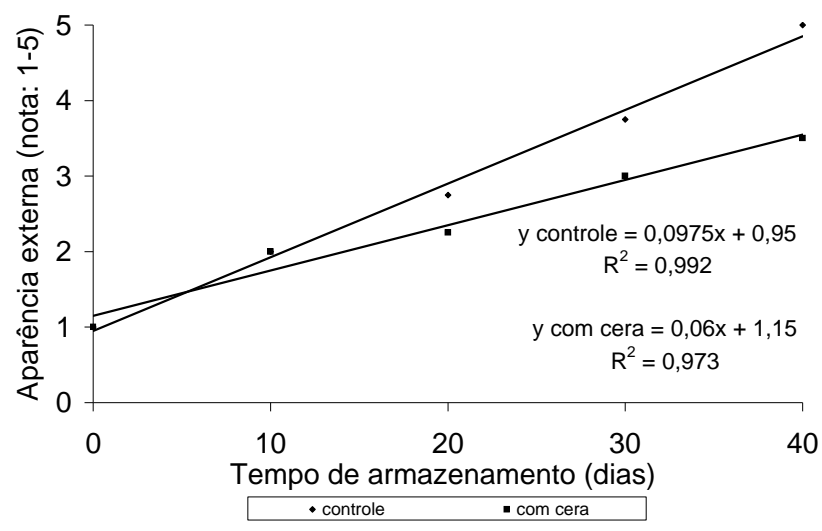

Figura 2 - Aparência de pomelo tratados com cera e armazenados sob diferentes períodos de armazenamento refrigerado $\left(8^{\circ} \mathrm{C} \pm 1^{\circ} \mathrm{C} ; 95 \% \pm 5 \% \mathrm{UR}\right)$. Notas de 1-5; $1: 0 \%$ de danos; $2: 1-25 \% ; 3: 26-50 \% ; 4: 51-75 \%$; e 5: 76-100\% de frutos afetados por enrugamento.

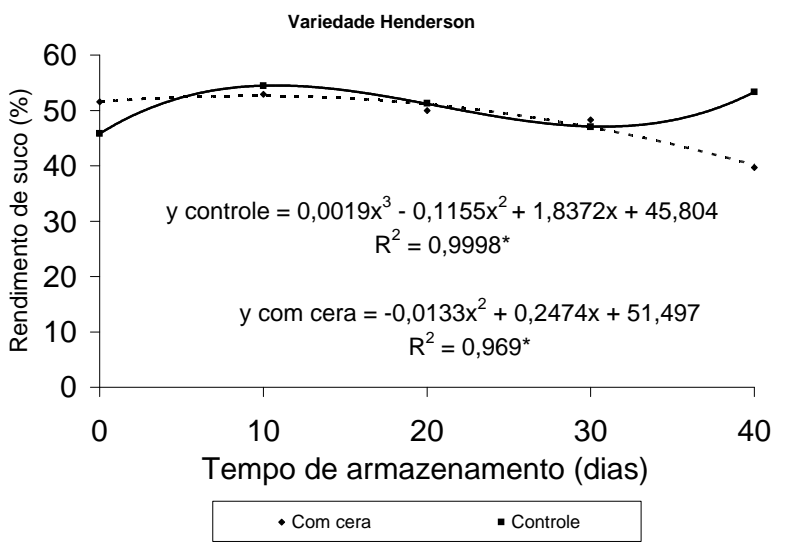

Figura 3 - Rendimento de suco de pomelo 'Henderson' sob diferentes períodos de armazenamento refrigerado $\left(8^{\circ} \mathrm{C} \pm\right.$ $\left.1^{\circ} \mathrm{C} ; 95 \% \pm 5 \% \mathrm{UR}\right)$. 
Nem a aplicação da cera, tampouco o tempo de armazenamento influenciaram a variável $\mathrm{pH}$ nos frutos das duas variedades estudadas, observando-se valor médio de 3,26 para a 'Flame' e 3,28 para a 'Henderson'. Durante o período de armazenamento, os valores de $\mathrm{pH}$ não apresentaram diferenças nas duas variedades estudadas, provavelmente por causa da capacidade tamponante do fluido intracelular, preservando as condições ideais para o metabolismo do fruto (Wills et al., 1998).

A acidez titulável (AT) nos frutos da variedade Flame não foi influenciada pelo tratamento com cera, tampouco pelo tempo de armazenamento. A acidez titulável média observada foi de 1,40\% de ácido cítrico. Já, para a variedade 'Henderson', a AT foi influenciada pelo período de armazenamento (Figura 4). Observou-se decréscimo linear na AT ao longo do armazenamento de 1,52\% para 1,27\% de ácido cítrico. Essa redução da acidez, durante o armazenamento do fruto, pode ser associada à sua utilização na respiração ou conversão em açúcares (Wills et al., 1998). Os valores de AT, para as duas variedades estudadas, foram inferiores aos descritos por Donadio \& Enciso-Garay (1997) e Lederman et al. (2005).

Os teores de sólidos solúveis ( $\mathrm{SS}$ ) foram influenciados pela interação entre os fatores cera e tempo de armazenamento, nas variedades Flame e Henderson (Figuras 5A e B). Os teores de SS aumentaram de forma linear de $7,83 \%$ para $9,27 \%$, ao longo armazenamento, nos frutos 'Flame' revestidos com cera, enquanto comportamento quadrático foi observado nos frutos controle, com maior valor $(8,58 \%)$ verificado no $30^{\circ}$ dia. A leve redução no teor de SS, no final do armazenamento $(8,28 \%)$, sugere que esses sólidos estão sendo mais usados na respiração do que produzidos (Figura 5A). Já, nos frutos 'Henderson', sob efeito de cera, os teores de SS apresentaram-se relativamente estáveis durante o período de armazenamento e nos frutos controle não foi possível ajuste, havendo oscilação ao longo do armazenamento com incremento de $7,43 \%$ para $8,45 \%$ até o $20^{\circ}$ dia (Figura $5 \mathrm{~B}$ ).

Coelho (2002), analisando pomelo 'Marsh Seedless “ observou $8,6 \%$ de sólidos solúveis, resultado semelhante aos encontrados no presente trabalho. Lederman et al. (2005) encontraram valores superiores, estudando pomelos 'Marsh Foster' (11,0\%), 'Star Ruby' (14,2\%), 'Rio Red“ (9,3\%), 'Red Blush` (10,9\%), 'Marsh Foster Nucelar` $(9,2 \%)$ e 'Triumph'(10,4\%).

A relação sólidos solúveis/acidez titulável (SS/AT) foi influenciada apenas pelo período de armazenamento para as duas variedades (Figura 6A e B). Verificou-se incremento na SS/AT de 5,49 a 6,59 para variedade Flame (Figura 6A) e de 5,17 a 6,51, para a variedade Henderson (Figura 6B), durante o armazenamento. A SS/AT foi superior à citada por Donadio \& Enciso-Garay (1997) para as variedades 'Star Ruby ' (5,08), 'Redblush' $(4,60)$, 'Marsh Seedless‘ 10 (4,60), M.S.21 (4,62), M.S.C $(4,67)$ e M.S. P $(4,90)$, que relaciona a baixa SS/AT à época de colheita (junho-julho), razão pela qual deve-se retardar a colheita para que sejam obtidos valores maiores.

Coelho (2002), analisando a SS/AT em pomelo 'Marsh Seedless', observou 6,01, enquanto Lederman et al. (2005) observaram diferenças entre pomelos das variedades, 'Marsh Foster' (6,28\%), 'Star Ruby' (5,26\%), 'Rio Red` (5,88\%), 'Red Blush` (5,67\%), 'Marsh Foster Nucelar' $(6,10 \%)$ e 'Triumph' (6,19\%), valores semelhantes aos observados no presente trabalho. A relação SS/AT é um dos índices mais utilizados para se determinar a maturação e a palatabilidade dos frutos. Chitarra \& Chitarra (2005) estabelecem que essa relação é indicativa do sabor que se acentua à medida que ocorre o amadurecimento.

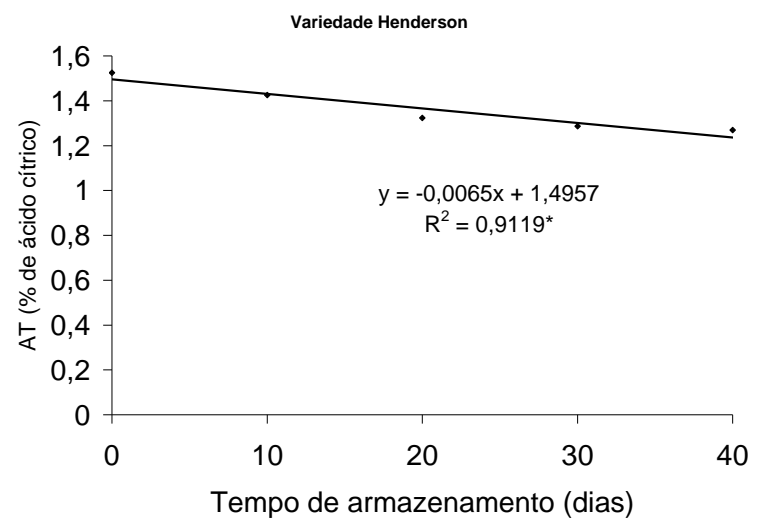

Figura 4 - Acidez titulável de pomelo 'Henderson' sob diferentes períodos de armazenamento refrigerado $\left(8^{\circ} \mathrm{C} \pm 1^{\circ} \mathrm{C}\right.$; $95 \% \pm 5 \%$ UR). 

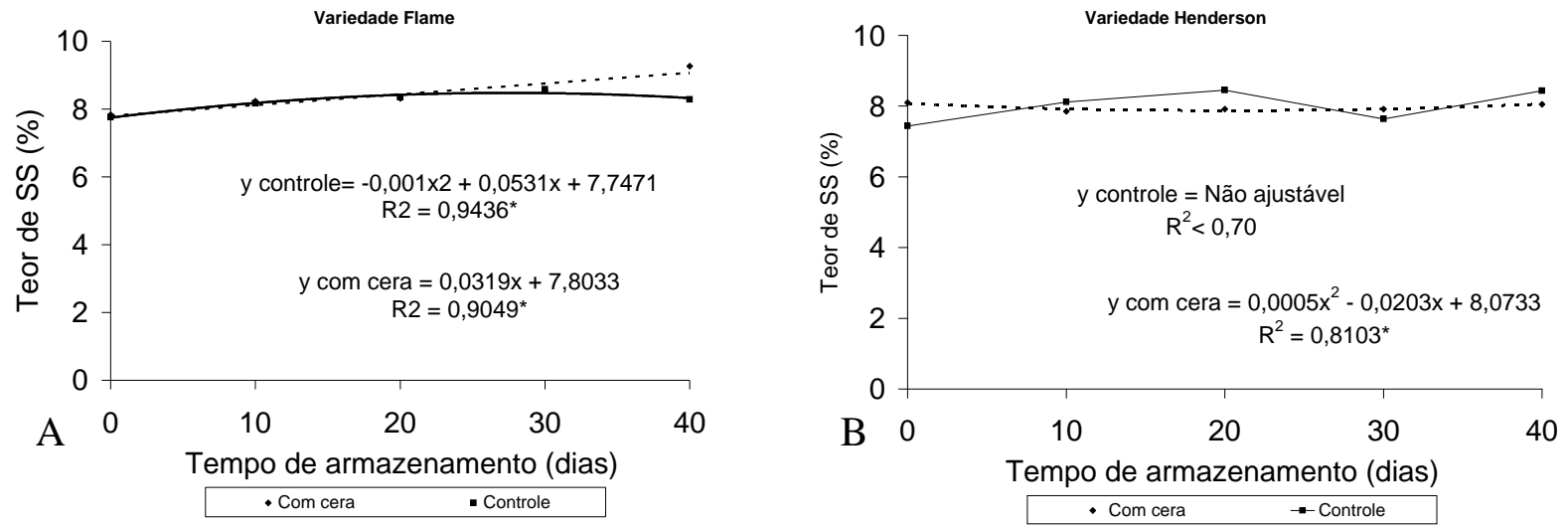

Figura 5 - Teor de sólidos solúveis (SS) de pomelos 'Flame' (A) e 'Henderson' (B) sob diferentes períodos de armazenamento refrigerado $\left(8^{\circ} \mathrm{C} \pm 1^{\circ} \mathrm{C} ; 95 \% \pm 5 \% \mathrm{UR}\right)$.
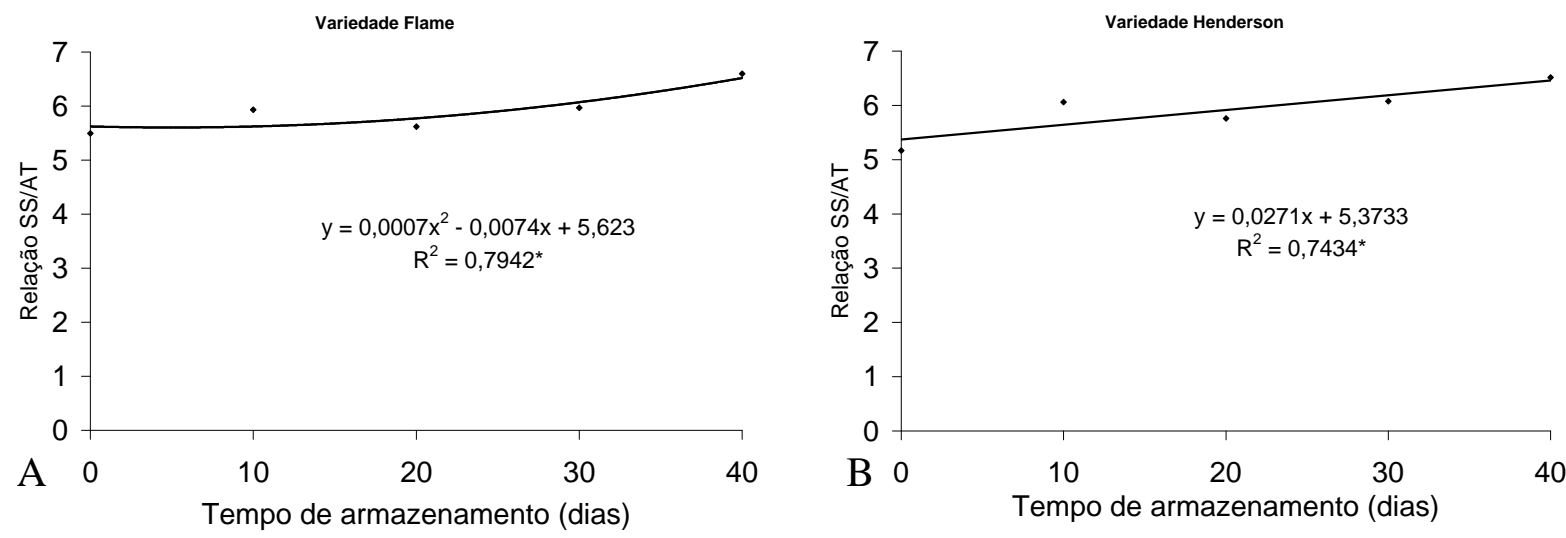

Figura 6 - Relação SS/AT de pomelos 'Flame' (A) e 'Henderson' (B) sob diferentes períodos de armazenamento refrigerado $\left(8^{\circ} \mathrm{C} \pm 1^{\circ} \mathrm{C} ; 95 \% \pm 5 \% \mathrm{UR}\right)$.

O teor de açúcares solúveis totais (AST) foi influenciado, na variedade Flame, pela interação dos fatores tempo de armazenamento e tratamento com cera. Observou-se ajuste quadrático para ambos os tratamentos, sendo que o menor teor foi registrado aos 25 dias, quando se aplicou cera e o maior teor foi registrado aos 14 dias, nos frutos controle (Figura 7A). A aplicação da cera nos frutos 'Henderson' não influenciou o teor de AST, que variou apenas em função do período de armazenamento (Figura 7B). Observou-se um comportamento quadrático, com tendência de redução de 7,20\% para 6,09\% até o $30^{\circ}$ dia, seguido de aumento.

$\mathrm{O}$ teor de açúcares redutores (AR) foi influenciado apenas pelo tempo de armazenamento, em pomelo 'Flame". Durante o período de armazenamento, os valores de AR dos frutos de todos os tratamentos diminuíram de 2,62\% para $1,19 \%$ significativamente, ao longo do armazenamento (Figura 8A). Já, nos frutos 'Henderson', o teor de AR foi influenciado pela interação entre os fatores. O teor de AR oscilou ao longo do armazenamento, em torno de $2 \%$, embora nenhum ajuste tenha sido obtido, a despeito do uso de cera (Figura 8B). Wills et al. (1998) relataram que aumentos nos teores de açúcares redutores durante o amadurecimento de frutos podem ser decorrentes da perda de água e hidrólise de polissacarídeos, hemicelulose e substâncias pécticas da parede celular.

Os teores dos açúcares não redutores (ANR) nos frutos 'Flame' e 'Henderson' foram influenciados pela interação entre os fatores tempo de armazenamento e tratamento com cera. Observou-se, para os frutos 'Flame' tratados com cera, diminuição nos valores da variável até 
o $18^{\circ}$ dia, seguida de incremento (Figura 9A). Já, nos frutos 'Flame' controle não foi obtido ajuste, sendo que os valores de ANR oscilaram durante o período, de 5,14 a 4,93\%. Para os frutos 'Henderson' não foi obtido nenhum ajuste, apesar de os teores de ANR nos frutos com cera oscilarem de $5,33 \%$ a $5,05 \%$ e nos frutos controle, de $4,87 \%$ a $4,95 \%$ (Figura 9B).

$\mathrm{O}$ teor de vitamina $\mathrm{C}$ foi influenciado apenas pelo tempo de armazenamento, em pomelos 'Flame" e 'Henderson'. Os teores de vitamina C nos frutos 'Flame' aumentaram de 48,21 para 71,51 mg de ácido ascórbico $100 \mathrm{~g}^{-1}$ de polpa, ao longo do armazenamento (Figura 10A), sendo que nenhum ajuste foi obtido para frutos 'Henderson', verificando-se uma variação de 57,51 a 60,47 mg de ácido ascórbico $100 \mathrm{~g}^{-1}$ de polpa (Figura 10B). As concentrações altas estão relacionadas à maior síntese de intermediários metabólicos precursores do ácido ascórbico e as baixas concentrações, à oxidação dos ácidos orgânicos durante o amadurecimento. Os valores apresentados neste trabalho para as duas variedades estão superiores aos observados por Vanderslice et al. (1990) que esteve em torno de 23,6 mg de ácido ascórbico $100 \mathrm{~g}^{-1}$ de polpa.
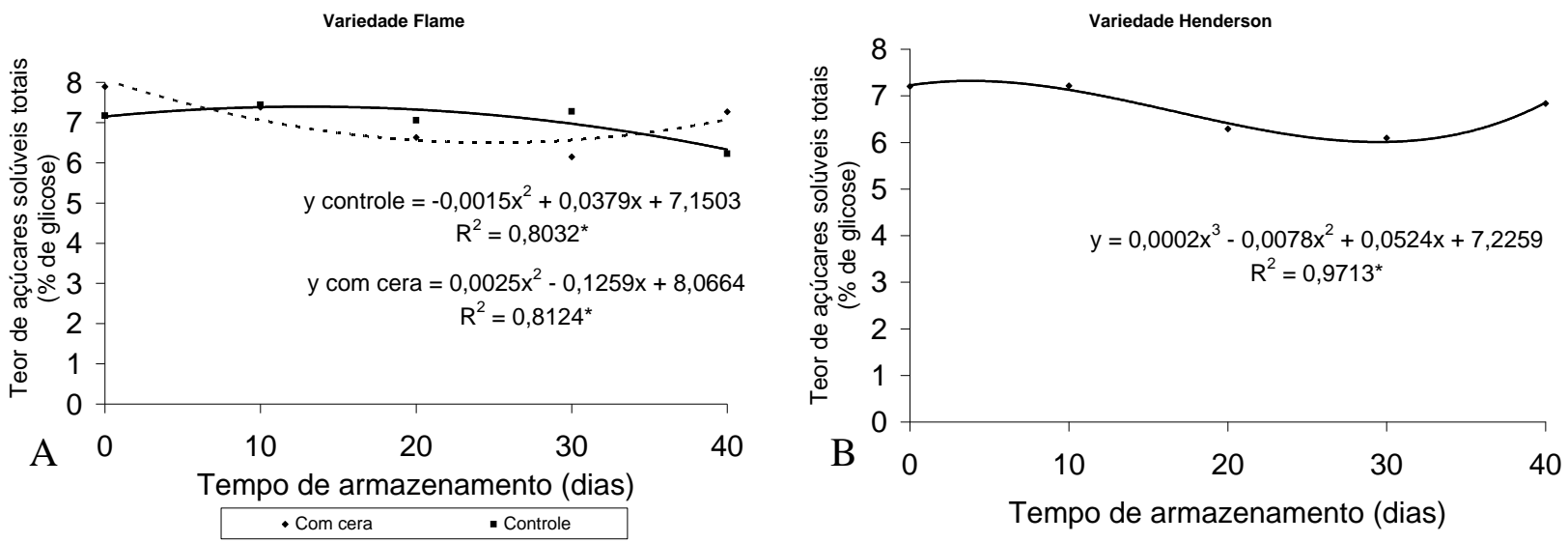

Figura 7 - Teor de açúcares solúveis totais de pomelos 'Flame' (A) e 'Henderson' (B) sob diferentes períodos de armazenamento refrigerado $\left(8^{\circ} \mathrm{C} \pm 1^{\circ} \mathrm{C} ; 95 \% \pm 5 \% \mathrm{UR}\right)$.
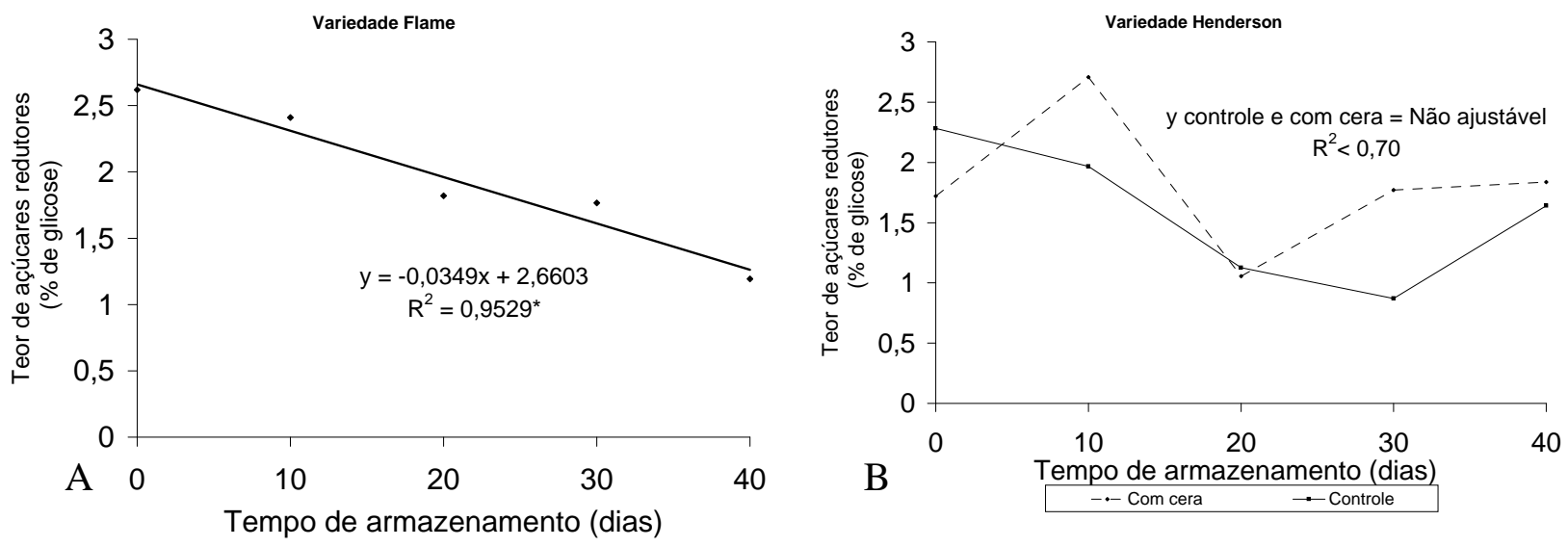

Figura 8 - Teor de açúcares redutores de pomelos 'Flame' (A) e 'Henderson' (B) sob diferentes períodos de armazenamento refrigerado $\left(8^{\circ} \mathrm{C} \pm 1^{\circ} \mathrm{C} ; 95 \% \pm 5 \% \mathrm{UR}\right)$. 

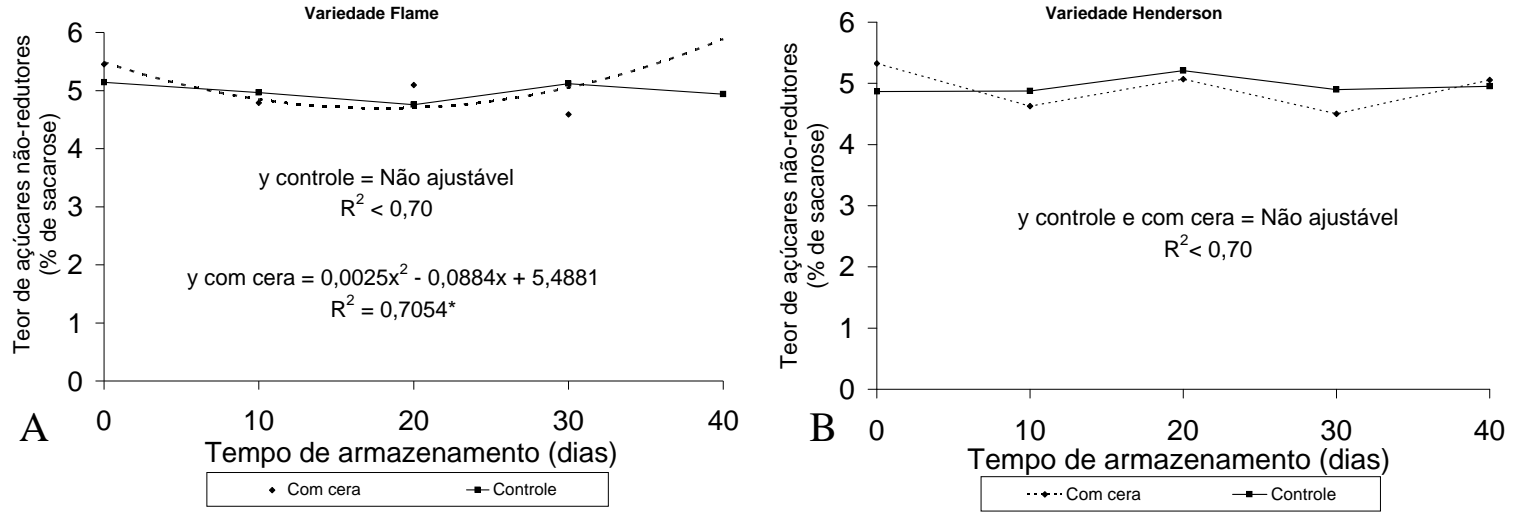

Figura 9 - Teor de açúcares não-redutores de pomelos 'Flame' (A) e 'Henderson' (B) sob diferentes períodos de armazenamento refrigerado $\left(8^{\circ} \mathrm{C} \pm 1^{\circ} \mathrm{C} ; 95 \% \pm 5 \% \mathrm{UR}\right)$.
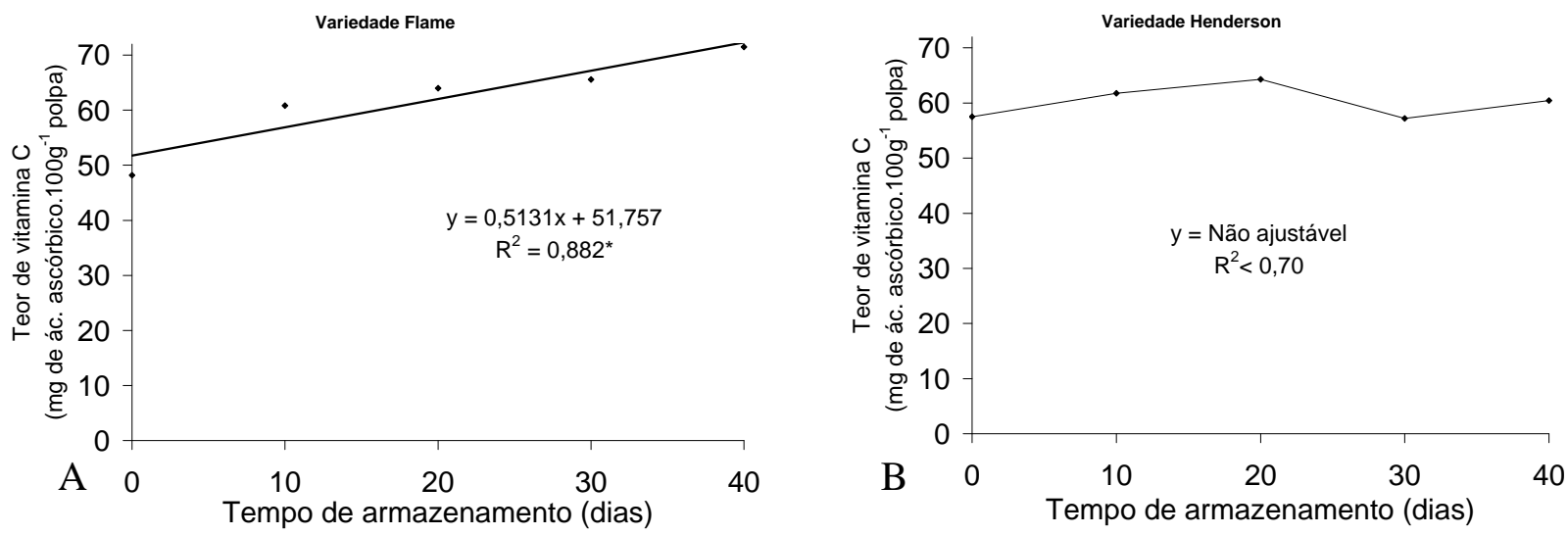

Figura 10 - Vitamina C de pomelos 'Flame' (A) e 'Henderson' (B) sob diferentes períodos de armazenamento refrigerado $\left(8^{\circ} \mathrm{C} \pm 1^{\circ} \mathrm{C} ; 95 \% \pm 5 \% \mathrm{UR}\right)$.

\section{CONCLUSÕES}

Conclui-se que a aplicação de cera Sparcitrus é efetiva na preservação da aparência de pomelos 'Flame' e 'Henderson', não afetando sua qualidade interna.

A cera Sparcitrus apresentou maior eficiência na conservação pós-colheita de frutos de pomelo, em função da menor percentagem de perda de massa dos frutos e consequente enrugamento, além de manter os frutos em boas condições para a comercialização.

\section{REFERÊNCIAS BIBLIOGRÁFICAS}

ASSOCIATION OF OFFICIAL ANALYTICAL CHEMISTRY. Official methods of analysis of the Association of Official Analytical Chemistry. 12.ed. Washington, 1992. 1015p.
CHITARRA, M.I.F.; CHITARRA, A.B. Pós-colheita de frutos e hortaliças: fisiologia e manuseio. 2.ed. rev. e ampl. Lavras: UFLA, 2005. 785p.

COELHO, Y. Frutas cítricas importadas no mercado de Salvador, Bahia. Bahia Agrícola, Salvador, v.5, n.2, p.2933, nov. 2002.

DAMIANI, C.; VILAS-BOAS, E.V. de B.; PINTO, D.M. Processamento mínimo de tangerinas armazenadas sob duas temperaturas. Ciência e Agrotecnologia, Lavras, v.32, n.1, p.308-313, 2008a.

DAMIANI, C.; VILAS-BOAS, E.V. de B.; PINTO, D.M.; RODRIGUES, L.J. Influência de diferentes temperaturas na manutenção da qualidade de pequi minimamente 
processado. Ciência e Agrotecnologia, Lavras, v.32, n.1, p.203-212, 2008 b.

DONADIO, L.C.; ENCISO-GARAY, C.R. Avaliação de variedades de pomelo em Bebedouro(SP). Laranja, Cordeirópolis, v.18, n.1, p.175-188, 1997.

EVANGELISTA, R.M.; CHITARRA, A.B.; CHITARRA, M.I.F. Influência da aplicação pré-colheita de cálcio na textura e na atividade das enzimas poligalacturonase, pectinametilesterase e $\beta$-galactosidase de mangas 'Tommy atkins', armazenadas sob refrigeração. Ciência Agrotecnologia, Lavras, v.24, n.1, p.174-181, 2000.

FOOD AND AGRICULTURE ORGANIZATION. FAOSTAT database results. Disponível em: <http:// apps1.fao.org?. Acesso em: 6 jul. 2007.

INSTITUTO ADOLFO LUTZ. Normas Analíticas, métodos químicos e físicos para análise de alimentos. 3.ed. São Paulo, 1985. v.1, 533p.

LEDERMAN, I.E.; BEZERRA, J.E.F.; ALVES, M.A.; COELHO, Y.S.; SOBRINHO, A.P. C. Comportamento de seis variedades de pomelo (Citrus paradisi Macfad.) cultivadas sob irrigação na região semi-árida de Pernambuco. Revista Brasileira Fruticultura, Jaboticabal, v.27, n.2, p.245-247, ago. 2005.

LIMA, M.A.C. de; ALVES, R.E.; FILGUEIRAS, H.A.C. Comportamento respiratório e amaciamentode graviola (Annona muricata L.) após tratamentos pós-colheita com cera e 1-metilciclopropeno. Ciência e

Agrotecnologia, Lavras, v.34, n.1, p.155-162, 2010.

MOTA, W.F.; SALOMÃO, L.C.C.; NERES, C.R.L.; MIZOBUTSI, G.P.; NEVES, L.L.M. Uso de cera de carnaúba e saco plástico poliolefínico na conservação pós-colheita do maracujá-amarelo. Revista Brasileira de Fruticultura, Jaboticabal, v.28, n.2, p.190-193, ago. 2006.

NELSON, N.A. A photometric adaptation of Somoghy method for the determination of glucose. Journal of Biological Chemistry, Baltimore, v.135, n.1, p.136-175, 1944.

OLIVEIRA, M.A.; SANTOS, C.H.; HENRIQUE, C.M.; RODRIGUES, J.D. Ceras para conservação pós-colheita de frutos de abacateiro cultivar Fuerte, armazenados em temperatura ambiente. Scientia Agrícola, Piracicaba, v.57, n.4, p.777-780, out./dez. 2000.

PINHEIRO, A.C.M.; VILAS-BOAS, E.V. de B.; SILVA, L.C. e; ALVES, A.P.; LA SELVA, M.; CHITARRA, A.B. Quality of fresh-cut avocado (Persea americana Mill) stored under different temperatures. Ciência e Agrotecnologia, Lavras, v.33, n.4, p.1095-1102, 2009.

SIMÃO, S. Tratado de fruticultura. Piracicaba: FEALQ, 1998. 760p.

STROHECKER, R.L.; HENNING, H.M. Analysis de vitaminas: métodos comprobados. Madrid: Paz Montalvo. 1967. 428p.

VANDERSLICE, J.T.; HIGGS, D.J.; HAYES, J.M.; BLOCK, G. Ascorbic acid and dehydroascorbic acid content of foods-as-eaten. Journal of Food Composition and Analysis, Amsterdam, v.3, p.105-118, 1990.

WILLS, R.; McGLASSON, B.; GRAHAM, D.; JOYCE, D. Introducción a la fisiologia y manipulación poscoseha de frutas, hortalizas y plantas ornamentales. 2.ed. Zaragoza: Acribia, 1998. 240p. 